\title{
Composição corporal e exigências de proteína para ganho de peso de caprinos Moxotó em crescimento ${ }^{1}$
}

\author{
Kaliandra Souza Alves ${ }^{2}$, Francisco Fernando Ramos de Carvalho ${ }^{3}$, Antonia Sherlânea \\ Chaves Véras ${ }^{3}$, Ângela Maria Vieira Batista ${ }^{3}$, Carla Wanderley Mattos ${ }^{4}$, Roberto Germano \\ Costa $^{5}$, Rinaldo José de Souto Maior Júnior ${ }^{6}$
}

\author{
${ }^{1}$ Pesquisa financiada pelo CNPq. \\ 2 PDIZ (UFRPE/UFPB/UFC)/UDP - UFRA Carajás. \\ ${ }^{3}$ Departamento de Zootecnia/UFRPE (Bolsista de Produtividade em Pesquisa do CNPq). \\ ${ }^{4}$ Programa de Pós-Graduação/UFRPE (Mestrado em Zootecnia). \\ 5 Departamento de Zootecnia/UFPB/Campus Areia (Bolsista de Produtividade em Pesquisa do CNPq). \\ ${ }^{6}$ Graduação em Zootecnia/UFPRE. Bolsista PIBIC/CNPq.
}

RESUMO - Avaliaram-se a composição corporal e as exigências de proteína para ganho de peso de caprinos da raça Moxotó. Utilizaram-se 26 animais machos não-castrados, com peso vivo (PV) médio inicial de $15 \mathrm{~kg}$ e 7 a 8 meses de idade, alimentados com dieta contendo 2,6 Mcal de energia metabolizável. Ao início do experimento, seis animais foram abatidos e serviram como referência para estimativa da composição corporal e do peso de corpo vazio (PCVZ) iniciais Posteriormente, formaram-se grupos homogêneos de quatro animais, distribuídos ao acaso em dois programas de alimentação (tratamentos): alimentação à vontade (AV); e restrição alimentar de 85, 70 e 55\% do consumido pelo grupo com alimentação à vontade. Os animais com AV foram abatidos no momento em que o PV se aproximou de $25 \mathrm{~kg}$. As equações do logaritmo (log) dos conteúdos corporais de proteína (CCP) foram ajustadas considerando o log do PCVZ. Derivando-se essa equação, obteve-se a equação de predição do conteúdo de proteína por kg de ganho de PCVZ. Os conteúdos protéicos dos animais experimentais mantiveram-se praticamente constantes e variaram de 205,60 para 201,69 g/kg de PCVZ (redução de 1,9\%) e de 15 para $25 \mathrm{~kg}$ com o aumento do PV. Apesar da pouca variação corporal das exigências líquidas protéicas (19,86 para 19,49), a relação gordura:proteína aumentou com o aumento do PV de 15 para 25 kg.

Palavras-chave: cabras nativas, exigências, peso do corpo vazio, proteína metabolizável

\section{Body composition and protein requirements for weight gain of growing Moxotó kids}

\begin{abstract}
Twenty-six Moxotó non-castrated male kids (initial mean $15 \mathrm{~kg} \mathrm{LW}$ and 7-8 month old) fed a diet with 2.6 Mcal ME were used to evaluate the body composition and protein requirements for weight gain. At the beginning of the experiment, six animals were slaughtered as reference to estimate initial body composition and initial empty body weight (EBW). Subsequently, homogeneous groups of four animals were distributed a complete randomized experimental design into two feeding regimes: ad libitum feeding (AL) and feed restriction of 85,70 and $55 \%$ of that consumed by the AL feeding group. The animals from each feeding regime were slaughtered at the time the group of the AL feeding approached $25 \mathrm{~kg}$ LW. Logarithm equation of retained body protein contents (BCP) was fitted on log10 of empty body weight (EBW). By deriving this equation, the predicting equation of BCP per kg of EBW gain was obtained. The protein content of the animals remained practically constant and ranged from 205.60 to $201.69 \mathrm{~g} / \mathrm{kg}$ of EBW (reduction of 1.9\%) and 15 to $25 \mathrm{~kg}$ with the increase of live weight. Despite of small body changes of net protein requirements (19.86 to 19.49), the fat: protein ratio increased with the increase in LV from 15 to $25 \mathrm{~kg}$.
\end{abstract}

Key Words: empty body weight, metabolizable protein, native goats, requirement

\section{Introdução}

O crescimento é uma das formas mais importantes de produção animal, porque, além de influenciar as demais funções exploradas pelo homem nas espécies domésticas, caracteriza-se como um processo de desenvolvimento corporal de elevada eficiência, praticado em animais jovens.

Tão importante quanto à de outros nutrientes, a determinação dos requerimentos protéicos é imprescindível (Valadares Filho et al., 2005). A inexistência de dados 
referentes às exigências protéicas de caprinos naturalizados, especialmente a raça Moxotó, para formulação adequada de rações, tem levado à utilização de resultados obtidos com caprinos de raças européias, geralmente criados em regiões de temperaturas mais baixas.

Também são utilizadas tabelas de dados internacionais para cálculos de rações, tradicionalmente conhecidas pelo boletim do Nutrient Requirements of Goats (NRC, 1981), que geralmente considera essas exigências como iguais às de bovinos e ovinos (Resende et al., 2001), ou mais recentemente, AFRC (1998). Todavia, inúmeros trabalhos têm mostrado que existem grandes diferenças entre as espécies (Medeiros, 2001). Possivelmente, estas devem ser as razões para as diferentes taxas de ganho de peso de animais quando essas recomendações são utilizadas na elaboração de rações (Teixeira, 2004).

A determinação da composição corporal dos animais é fundamental para a avaliação do valor nutricional dos alimentos e para estudos do crescimento animal (Boin et al., 1994), pois possibilita a estimativa das exigências de proteína para o ganho de peso dos animais (Putrino et al., 2006).

Os requerimentos protéicos são afetados pela idade, pelo sexo, pelo estádio fisiológico, pela taxa de crescimento e pela composição corporal, entre outros fatores (ARC, 1980; Geay, 1984; AFRC, 1998). Além disso, o genótipo tem grande influência sobre a composição corporal e as taxas de crescimento (Garret, 1980; Ferrell \& Jenkins, 1998).

As exigências líquidas de proteína para animais em crescimento são funções do conteúdo de matéria seca livre de gordura no ganho de peso (Valadares Filho et al., 2005). São maiores para animais não-castrados e, dentro de um mesmo sexo, são maiores para animais de maturidade tardia que para os de maturidade precoce (Geay, 1984), em decorrência do maior potencial para crescimento muscular de animais não-castrados e/ou de maturidade tardia.

Alguns trabalhos foram realizados no Brasil objetivando determinar a composição e exigência líquida de proteína para caprinos em crescimento. Medeiros (2001), estudando caprinos da raça Saanen, e Teixeira (2004), trabalhando com mestiços Boer $\times$ Saanen em crescimento, estimaram concentração de proteína no corpo vazio de 173,6 a 180 e de 178 a 193,4 g/kg PCVZ, respectivamente.

Os resultados encontrados no Brasil para exigências de proteína para ganho em PCVZ variam de 177 a 232 g/kg PCVZ (Souza et al., 1998; Medeiros, 2001; Ferreira, 2003; Teixeira, 2004).

O NRC (1981) estabelece a exigência de proteína para ganho como a média de três valores obtidos em três trabalhos, de 0,284 g de proteína bruta/g de ganho de PV, enquanto o AFRC (1993) sugere, para machos castrados, a equação: concentração de proteína líquida [PL] (g/kg de ganho de PV) $=157,22-0,694 P V$. Dessa forma, utilizando-se a equação sugerida por este comitê para cabritos castrados de $20 \mathrm{~kg}$ de PV, a exigência de proteína no ganho é de 143,34 g/dia.

O crescimento é o mais avaliado, principalmente no Brasil. Na maioria das pesquisas, utilizaram-se raças leiteiras exóticas e animais mestiços envolvendo essas raças, assim como mestiços de raças de corte.

Objetivou-se com esta pesquisa estimar as exigências de proteína para ganho de caprinos da raça Moxotó.

\section{Material e Métodos}

O experimento foi conduzido no Departamento de Zootecnia da Universidade Federal Rural de Pernambuco UFRPE, localizada em Recife, Pernambuco.

Foram utilizados 26 animais machos da raça Moxotó, não-castrados e com 7 a 8 meses de idade, que foram identificados, tratados contra ecto e endoparasitas e alojados individualmente em baias medindo $1,0 \mathrm{~m} \times 2,80 \mathrm{~m}$, confeccionadas em alvenaria e chão batido e providas de comedouros e bebedouros. Os animais receberam uma dieta contendo 2,6 Mcal de energia metabolizável (EM) durante aproximadamente 30 dias, que compreendeu o período de adaptação. Quando os animais atingiram $15 \mathrm{~kg}$ de PV, deu-se início ao período experimental.

Inicialmente, seis animais foram abatidos e serviram como referência no estudo da composição corporal e do peso do corpo vazio (PCVZ) iniciais. Em seguida, formaram-se cinco grupos de quatro animais, distribuídos ao acaso em cada tratamento que consistiu de: alimentação à vontade (AV) e alimentação restrita (AR) a 85,70 e $55 \%$ do consumido pelo grupo que recebeu a AV. Durante essa fase, foi efetuado ajuste de $20 \%$ das sobras apenas para os animais que recebiam $\mathrm{AV}$.

A ração utilizada (Tabela 1) foi constituída de $40 \%$ de volumoso (feno de capim-tifton 85, Cynodon dactylon), moído em máquina forrageira com peneira de crivo de $4 \mathrm{~mm}$ e $60 \%$ de concentrado à base de milho, farelo de soja, farelo de trigo, óleo vegetal, calcário e suplemento mineral.

A ração foi formulada para atender às exigências para ganhos de peso médios diários de $150 \mathrm{~g} / \mathrm{animal} /$ dia, segundo o NRC (1981). O fornecimento das rações experimentais foi realizado às 8 e 15 h, conforme pré-estabelecido, com água permanentemente à disposição dos animais. Antes da oferta matinal, foram coletadas as sobras de cada unidade experimental, que, depois de pesadas, registradas e amostradas, 
Tabela 1 - Composição da ração experimental

\begin{tabular}{lc}
\hline Ingrediente & $\%$ na MS \\
\hline Feno de capim-tifton & 40,0 \\
Grão de milho moído & 22,1 \\
Farelo de soja & 18,4 \\
Farelo de trigo & 14,9 \\
Óleo vegetal & 2,0 \\
Cálcario calcítico & 1,6 \\
Sal mineral comercial & 1,0 \\
\hline
\end{tabular}

Composição da ração

Matéria seca, \%

Proteína bruta ${ }^{1}$ 94,0

Extrato etéreo ${ }^{1}$

19,5

4,8

Fibra em detergente neutro ${ }^{1} \quad 46,2$

Fibra em detergente ácido ${ }^{1} \quad$ 22,1

Matéria orgânica 1

Carboidratos totais $^{1} \quad 68,0$

Carboidratos não-fibrosos ${ }^{1} \quad 24,9$

Matéria mineral ${ }^{1} \quad$ 7,6

Energia metabolizável, Mcal/kg de $\mathrm{MS}^{2} \quad 2,6$

$\mathrm{Ca}^{1,3} 3$

$\mathrm{P}^{1,3}$

0,4

$1 \%$ na MS.

2 Obtida a partir da estimativa do NDT (NRC, 2001) e pelas relações: $1 \mathrm{~kg}$

de NDT $=4,409$ Mcal ED e EM = 81,7\% ED.

3 Estimado conforme descrito por Valadares Filho et al. (2002).

foram congeladas $\left(20^{\circ} \mathrm{C}\right)$ e armazenadas para formação de uma amostra composta por animal ao final do período.

Os animais foram pesados no início do experimento, ao final do período de adaptação e a cada 28 dias durante o período experimental. Pesagens intermediárias foram feitas quando o $\mathrm{PV}$ dos animais que recebiam $\mathrm{AV}$ se aproximou do peso determinado para abate, de $25 \mathrm{~kg}$, quando os animais apresentavam 11 a 12 meses de idade.

Antes do abate, os animais foram pesados para obtenção do PV. Depois, foram submetidos a jejum de alimentos sólidos por 18 horas e novamente pesados para obtenção do peso vivo ao abate (PVA). Depois do abate, os animais foam eviscerados e o conteúdo do trato gastrintestinal foi retirado para determinação do PCVZ.

Posteriormente, a metade do corpo vazio do animal, que compreendia de forma proporcional e homogênea carcaça, todos os órgãos, patas, cabeça, pele e sangue recolhido no momento da sangria, foi pesada e congelada, cortada em serra de fita, moída e homogeneizada para retirada de amostras de aproximadamente 250 g por animal. Em seguida, submeteram-se as amostras à desidratação em estufa de $105^{\circ} \mathrm{C}$, durante 72 horas, para determinação do teor de matéria seca gordurosa (MSG). As amostras foram desengorduradas por lavagens sucessivas com éter de petróleo para determinação da matéria seca pré-desengordu-rada (MSPD).
Seqüencialmente, as amostras foram processadas em moinho de bola e acondicionadas em recipientes plásticos para posteriores análises de gordura, nitrogênio total e matéria seca para eventuais correções de umidade, conforme descrito por Silva \& Queiroz (2002).

A gordura removida no pré-desengorduramento foi obtida pela diferença entre a MSG e a MSPD, cujo valor foi acrescentado aos resultados obtidos na determinação do extrato etéreo ainda contido na MSPD. Depois de obtidos os teores de proteína na MSPD e o peso da amostra submetida ao pré-desengorduramento, determinaram-se osrespectivos teores na matéria natural.

Inicialmente, o conteúdo corporal de proteína (CCP) do corpo foi determinado em relação à concentração percentual de proteína no corpo dos animais. Somente os animais que recebiam alimentação à vontade e os animais-referência foram utilizados na estimativa da composição corporal e do ganho. Os animais-referência foram utilizados para predição do PCVZ e composição corporal iniciais dos animais mantidos com alimentação à vontade

Os conteúdos corporais de proteína retidos no corpo dos animais foram preditos por meio da equação do logaritmo (log) dos conteúdos corporais de proteína em relação ao log do PCVZ, conforme o ARC (1980):

$$
\log y=a+b \log x+e \text {, }
$$

em que $\log y=\log$ na base 10 do conteúdo total da proteína no corpo vazio (g); a = efeito da média (intercepto); b = coeficiente de regressão do log do conteúdo de proteína em função do PCVZ; $\log x=\log$ do peso de corpo vazio (kg); $\mathrm{e}=$ erro aleatório.

Derivando-se a equação acima, obteve-se a equação de predição do conteúdo de proteína por kg de ganho de PCVZ. Dessa forma, as exigências líquidas de proteína para ganho de $1 \mathrm{~kg}$ de PCVZ correspondem aos respectivos conteúdos no ganho de corpo vazio a partir da equação:

$$
\mathrm{Y}^{\prime}=\text { b. } 10^{\mathrm{a}} \mathrm{X}^{(\mathrm{b}-1)} \text {, }
$$

em que $\mathrm{Y}^{\prime}=$ conteúdo de proteína (g) no ganho; a = intercepto da equação; $b$ = coeficiente de regressão da equação; $X=$ PCVZ (kg).

Para conversão das exigências líquidas para ganho de PCVZ em exigências líquidas para ganho em PV, utilizou-se a equação entre a relação de PV e PCVZ dos animais pertencentes aos grupos com alimentação à vontade e com alimentação restrita a $85 \%$.

As exigências de proteína metabolizável para ganho de peso foram determinadas considerando a eficiência de 0,59 reportada pelo AFRC (1998). Os resultados foram interpretados por meio de análises de variância e regressão utilizando-se o SAEG (UFV, 2001). 


\section{Resultados e Discussão}

A concentração de água no corpo dos animais (Tabela 2) foi inferior à relatada na literatura consultada (Medeiros, 2001; Ferreira, 2003; Teixeira, 2004), provavelmente em virtude da maior idade ao abate dos animais utilizados nessa pesquisa. As deposições de gordura, proteína e cinzas, conseqüentemente, foram superiores, uma vez que, com a maturidade, a porcentagem de água corporal diminui em detrimento dos demais nutrientes, especialmente a gordura.

A equação obtida para predição do peso de corpo vazio (PCVZ) em diferentes intervalos de peso, em relação ao peso vivo (PV), foi: PCVZ = - 1,7778 + 0,9352 PV. O coeficiente de determinação de 0,98 obtido na equação comprovou bom ajustamento e baixa dispersão dos dados. O PCVZ estimado a partir dessa equação para um animal com $25 \mathrm{~kg}$ de PV foi de 21,60 kg, próximo ao de 21,28 kg de PCVZ relatado por Ferreira (2003) para caprinos Saanen com mesmo peso.

Na estimativa da composição corporal e da composição do ganho de peso, foram utilizados somente os dados dos animais que receberam alimentação à vontade (AV), adicionados aos animais-referência. Esse procedimento foi definido considerando que é necessária a composição corporal de animais que tenham expressado todo o seu potencial de desenvolvimento.

Os parâmetros dessa equação e o coeficiente de determinação obtido (Tabela 3) indicaram bom ajustamento e baixa dispersão dos dados.

Os conteúdos protéicos dos animais (Tabela 4) experimentais mantiveram-se praticamente constantes (de 205,60 para 201,69 g/kg de PCVZ) e reduziram 1,9\% com o aumento do PV. Esse resultado se deve, provavelmente, ao fato de o experimento ter sido iniciado com animais com média de $15 \mathrm{~kg}$ de PV e 7 a 8 meses de idade, quando possivelmente já estariam estabelecendo o crescimento muscular e conseqüentemente apresentariam menor deposição protéica. A pouca variação na deposição do nutriente reflete nos tecidos de acordo com a fase de desenvolvimento. Essa pequena diferença na composição corporal atribuída à idade dos animais influencia as exigências líquidas.
Essa tendência contraria resultados reportados por Sanz Sampelayo et al. (1995) e Medeiros (2001), que verificaram deposição crescente de proteína no corpo vazio de acordo com o crescimento muscular, possivelmente porque utilizaram animais jovens (peso vivo inicial de 5,0 kg). Entretanto, Teixeira (2004) encontrou resposta decrescente para animais F1 Boer $\times$ Saanen pesando 15 a $25 \mathrm{~kg}$.

Ressalta-se que a deposição protéica observada neste estudo foi superior às encontradas por esses autores, possivelmente pelo fato de caprinos da raça Moxotó apresentarem maior deposição protéica, proporcional ao potencial de ganho de peso. Os animais experimentais foram criados em regime de confinamento com ração com 2,6 Mcal de energia metabolizável por kg de matéria seca. No entanto, a eficiência de ganho de peso para as condições em que foi executado o experimento pode ser considerada baixa, uma vez que o ganho de peso vivo foi de apenas $78 \mathrm{~g} /$ dia. Além disso, Geay (1984) relata que a deposição protéica é maior em animais não-castrados e, em mesmo sexo, é maior para animais de maturidade tardia em comparação aos de maturidade precoce, provavelmente em razão do maior potencial para crescimento muscular de animais não-castrados e/ou de maturidade tardia.

Apesar de os valores absolutos de deposição protéica (Tabela 5) terem apresentado pouca variação, constatou-se elevação de $59 \%$ na relação de gordura/proteína, fato observado também por Yáñez (2002) em cabritos da raça Saanen.

As proporções corporais alteraram com a redução na velocidade de crescimento muscular e o mais rápido desenvolvimento do tecido adiposo em relação ao PCVZ e/ou PV. A taxa de crescimento do tecido adiposo aumenta com a idade, conforme relatado por Berg \& Butterfield (1976), Grant \& Helferich (1991) e Owens et al. (1993). Assim, a deposição de proteína diminui e a de gordura aumenta com o maior peso do corpo (Andrade, 2006), portanto, as curvas de crescimento refletem a relação entre a idade do animal e seu impulso de crescimento e maturidade.

É fundamental conhecer o momento (peso e/ou idade) em que a taxa de crescimento muscular diminui e a maioria dos nutrientes é direcionada para deposição do tecido adiposo, pois esse tecido tem um custo energético mais

Tabela 2 - Composição corporal em água, gordura, proteína e cinza no peso do corpo vazio (PCVZ) de caprinos Moxotó em crescimento sob restrição alimentar

\begin{tabular}{lrrrrr}
\hline Composição corporal (\%) & \multicolumn{1}{c}{ Referência } & \multicolumn{1}{c}{$100 \%$} & \multicolumn{1}{c}{$85 \%$} & \multicolumn{1}{c}{$70 \%$} & $55 \%$ \\
\hline Água & $67,67 \pm 1,11$ & $62,12 \pm 3,24$ & $62,64 \pm 0,97$ & $61,20 \pm 2,34$ & $63,36 \pm 1,97$ \\
Gordura & $7,84 \pm 0,84$ & $13,32 \pm 4,05$ & $12,08 \pm 1,75$ & $14,22 \pm 2,69$ & $12,38 \pm 1,91$ \\
Proteína & $20,57 \pm 0,92$ & $20,37 \pm 0,97$ & $20,86 \pm 1,06$ & $19,90 \pm 1,23$ & $20,02 \pm 1,05$ \\
Cinza & $4,16 \pm 0,38$ & $4,38 \pm 0,34$ & $4,51 \pm 0,39$ & $4,67 \pm 0,33$ & $4,56 \pm 0,41$ \\
\hline
\end{tabular}


Tabela 3 - Equação de regressão do logaritmo (log) dos conteúdos de proteína (g) no corpo vazio em relação ao log do peso do corpo vazio $(\mathrm{kg})$ de caprinos Moxotó em crescimento

\begin{tabular}{ccc}
\hline \multicolumn{3}{c}{ Parâmetro } \\
\hline Intercepto (a) & Coeficiente (b) & $\mathrm{r}^{2} *$ \\
$-0,6502$ & 0,9662 & 0,98 \\
\hline
\end{tabular}

* Coeficiente de determinação.

Tabela 4 - Conteúdos de proteína no peso do corpo vazio (g/kg PCVZ) de caprinos Moxotó em crescimento, em relação ao peso vivo (PV) ou PCVZ

\begin{tabular}{lcc}
\hline PV $(\mathrm{kg})$ & PCVZ $(\mathrm{kg})$ & Proteína $(\mathrm{g} / \mathrm{kg}$ PCVZ) \\
\hline 15,00 & 12,25 & 205,60 \\
17,50 & 14,59 & 204,39 \\
20,00 & 16,93 & 203,36 \\
22,50 & 19,26 & 202,48 \\
25,00 & 21,60 & 201,69 \\
\hline
\end{tabular}

Tabela 5 - Estimativa da relação entre as concentrações corporais de proteína (PB) e gordura (G) no peso do corpo vazio (PCVZ) e peso vivo (PV) de caprinos Moxotó em crescimento

\begin{tabular}{lcccc}
\hline PV (kg) & PCVZ (kg) & \multicolumn{2}{c}{ Concentração $(\mathrm{g} / \mathrm{kg})$} & \multirow{2}{*}{ Relação (G/PB) } \\
\cline { 3 - 4 } & & $\mathrm{G}$ & $\mathrm{PB}$ & \\
\hline 15,00 & 12,25 & 78,55 & 205,6 & 0,38 \\
17,50 & 14,59 & 90,72 & 204,39 & 0,44 \\
20,00 & 16,93 & 102,54 & 203,36 & 0,50 \\
22,50 & 19,26 & 114,08 & 202,48 & 0,56 \\
25,00 & 21,60 & 125,38 & 201,69 & 0,62 \\
\hline
\end{tabular}

elevado e seu excesso acarreta desvalorização do produto comercializado (Yáñez, 2002). Portanto, é importante a realização de pesquisas com o propósito de recomendar a melhor eficiência de produção visando o aumento o retorno econômico da atividade.

Nesta pesquisa, animais da raça Moxotó com mais de 15 kg de PV diminuem a deposição protéica e aumentam linearmente o crescimento do tecido adiposo. Entretanto, as taxas de ganho dessa raça são muito baixas (Mattos, 2005) e não permitem que esses animais atinjam peso mínimo de abate de $25 \mathrm{~kg}$ em menor idade.

Para converter as exigências para ganho em PCVZ em exigências para ganho de $P V$, recomenda-se utilizar a equação encontrada, PCVZ = - 1,7778 + 0,9352 PV, entre a relação de PV e PCVZ dos animais pertencentes aos grupos que recebiam alimentação à vontade e alimentação restrita a 85\% (Tabela 6).
Tabela 6 - Equação de regressão para predição e exigências líquidas de proteína (g) por $100 \mathrm{~g}$ de ganho em peso do corpo vazio (GPCVZ) de caprinos Moxotó em crescimento, em relação ao peso de corpo vazio (PCVZ)

\begin{tabular}{lccc}
\hline Peso vivo $(\mathrm{kg})$ & PCVZ $(\mathrm{kg})$ & Equação de predição - Exigência $(\mathrm{g})$ \\
\cline { 3 - 4 } & & $\mathrm{Y}^{\prime}=0,216$. PCVZ $^{-0,0338}$ & $\mathrm{R}^{2}=0,98^{*}$ \\
\hline 15,00 & 12,25 & 19,86 & \\
17,50 & 14,59 & 19,74 & \\
20,00 & 16,93 & 19,64 & \\
22,50 & 19,26 & 19,56 & \\
25,00 & 21,60 & 19,49 & \\
\hline
\end{tabular}

* Coeficiente de determinação.

De modo geral, a maioria dos estudos indica redução nas exigências líquidas de proteína à medida que o peso corporal aumenta, contudo, refletindo a deposição no corpo, o conteúdo de proteína no ganho variou pouco e manteve-se praticamente constante (Tabela 6), com pouca diminuição com o aumento do PV e/ou PCVZ. Esse comportamento pode estar relacionado ao fato de os animais da raça Moxotó, seguindo a curva sigmóide de crescimento cumulativo, apresentarem nessa faixa de peso estabelecimento do crescimento muscular.

A deposição de proteína no ganho nos animais de $20 \mathrm{~kg}$ de PV foi de $0,196 \mathrm{~kg} / \mathrm{kg}$ de ganho de PV, portanto, 27\% superior ao valor de $0,143 \mathrm{~kg} / \mathrm{kg}$ de ganho de PV preconizado pela equação do AFRC (1993): (PLg) = 157,22-0,694PV, na qual PLg equivale à proteína líquida para ganho. Os resultados obtidos nesse estudo na faixa de peso de 20 a $25 \mathrm{~kg}$ de PV foram inferiores aos reportados por Ferreira (2003) e, na faixa de 15 a $20 \mathrm{~kg}$, foram superiores aos relatados pelo AFRC (1998), Medeiros(2001)e Teixeira(2004), queutilizaram em suas pesquisas animais castrados e não-castrados e comprovaram o potencial de caprinos da raça Moxotó em depositar tecido muscular e maior exigência de proteína para ganho, no entanto, caprinos Moxotó apresentam baixas taxas de ganho em peso.

Para conversão da proteína líquida em metabolizável, consideraram-se as recomendações do AFRC (1998), que preconiza valor de 0,59 para eficiência de utilização para ganho (kf) da proteína metabolizável.

As exigências de proteína metabolizável para ganho de PV obtidas neste experimento (Tabela 7) foram inferiores às relatadas pelo AFRC (1998) e às obtidas por Ferreira (2003), que observou para animais Saanem de 20 e $25 \mathrm{~kg}$ valores de 38,42 e 38,7g PMg/100g de ganho/animal/dia, respectivamente. 
Tabela 7 - Estimativa das exigências de proteína líquida e metabolizável para caprinos Moxotó em crescimento (g/animal/dia)

\begin{tabular}{lccc}
\hline Peso vivo & \multicolumn{3}{c}{ Ganho de peso vivo diário (g) } \\
\cline { 2 - 4 } & \multicolumn{4}{c}{100} & 150 \\
\hline & \multicolumn{3}{c}{ Proteína líquida para ganho (g) } \\
15,00 & 9,932 & 19,865 & 29,797 \\
17,50 & 9,874 & 19,748 & 29,622 \\
20,00 & 9,825 & 19,649 & 29,474 \\
22,50 & 9,782 & 19,563 & 29,345 \\
25,00 & 9,744 & 19,488 & 29,232 \\
\hline \multicolumn{5}{c}{ Proteína metabolizável para ganho $(\mathrm{g})$} \\
15,00 & 16,835 & 33,669 & 50,504 \\
17,50 & 16,736 & 33,471 & 50,207 \\
20,00 & 16,652 & 33,303 & 49,955 \\
22,50 & 16,579 & 33,158 & 49,737 \\
25,00 & 16,515 & 33,030 & 49,545 \\
\hline
\end{tabular}

${ }^{1}$ Eficiência de utilização da proteína metabolizável para ganho $=0,59$ (AFRC, 1998).

\section{Conclusões}

As exigências líquidas protéicas ou os conteúdos de proteína no ganho de corpo vazios de caprinos Moxotó entre 15 e 25 de PV apresentam pouca alteração com a elevação do PV ou PCVZ e variam de 19,865 para 19,488.

\section{Agradecimento}

Ao CNPq, pelo fomento dispensado a esta pesquisa, à Universidade Federal Rural de Pernambuco - UFRPE e ao Programa de Doutorado Integrado em Zootecnia - PDIZ (UFRPE-UFPB-UFC) do Departamento de Zootecnia da UFRPE, pelo apoio para a realização deste trabalho. Aos alunos de graduação que contribuíram na execução desta pesquisa.

À Universidade Federal Rural da Amazônia, por liberar-me das atividades acadêmicas para concluir o curso de Doutorado.

\section{Literatura Citada}

AGRICULTURAL AND FOOD RESEARCH COUNCIL - AFRC. Energy and protein requeriments of ruminants. Wallingford: Commonwealth Agricultural Bureaux International, 1993. 159p.

AGRICULTURAL AND FOOD RESEARCH COUNCIL - AFRC. Technical Committee on Responses to Nutrients, Report 10. The nutrition of goats. Aberdeen: Agricultural Food Research Council, 1998. v.67, n.11.

AGRICULTURAL RESEARCH COUNCIL - ARC The nutrient requirement of ruminant livestock. London: 1980. 351p.
ANDRADE, D.K.B. Composição corporal e exigências nutricionais de bovinos mestiços $5 / 8$ Holandês-Zebu sob pastejo na Zona da Mata de Pernambuco no período das águas. Recife: Universidade Federal Rural de Pernambuco, 2006. 65p. Tese (Doutorado em Zootecnia) - Universidade Federal Rural de Pernambuco, 2006.

BERG. R.T.; BUTTERFIELD, R.M. New concepts of cattle growth. New York: Sydney University, 1976. 240p.

BOIN, C.; LEME, P.R.; LANNA, D.P.D. et al. Tourinhos Nelore em crescimento e acabamento. 2. Exigências de energia líquida de mantença e eficiência de utilização da energia metabolizável para mantença e crescimento. In: REUNIÃO ANUAL DA SOCIEDADE BRASILEIRA DE ZOOTECNIA, 1994, Maringá. Anais... Maringá: Sociedade Brasileira de Zootecnia, 1994. p.473.

FERREIRA, A.C.D. Composição corporal e exigências nutricionais em proteína, energia e macrominerais de caprinos saanen em crescimento. Jaboticabal: Universidade Estadual Paulista, 2003. 86p. Tese (Doutorado em Zootecnia) Universidade Estadual Paulista, 2003.

FERRELL, C.L.; JENKINS, T.G. Body composition and energy utilization by steers of diverse genotypes fed a high-concentrate diet during the finishing period: II. Angus, Boran, Brahman, Hereford, and Tuli sires. Journal of Animal Science, v.76, p.647-657, 1998.

GARRETT, W.N. Factors influencing energetic efficiency of beef production. Journal of Animal Science, v.51, n.6, p.14341440, 1980.

GARRETT, W.N.; MEYER, J.H.; LOFGREEN, J.P. The comparative energy requirements of sheep and cattle for maintenance and gain. Journal of Animal Science, v.18, n.2, p.528-547, 1959.

GEAY, Y. Energy and protein utilization in growing cattle. Journal of Animal Science, v.58, n.3, p.766-778, 1984.

GONZAGA NETO, S.; SILVA SOBRINHO, A.G.; RESENDE, K.T. et al. Composição corporal e exigências nutricionais de proteína e energia para cordeiros Morada Nova. Revista Brasileira de Zootecnia, v.34, n.6, p.2446-2456, 2005 (supl.).

GRANT, A.L.; HELFERICH, W.G. An overview of growth. In: PEARSON, A.M.; DUTSON, T.R. (Eds.). Growth regulation in farm animals. London: Elsevier Applied Science, 1991. p.1-15.

MATTOS, C.W. Desempenho e características de carcaça de caprinos Moxotó e Canindé, em crescimento, submetidos a dois níveis de alimentação. Recife: Universidade Federal Rural de Pernambuco, 2005. 91p. Dissertação (Mestrado em Zootecnia) - Universidade Federal Rural de Pernambuco, 2005.

MEDEIROS, A.N. Estimativa da composição corporal e exigências em proteína e energia para caprinos Saanen na fase inicial de crescimento. Jaboticabal: Universidade Estadual Paulista, 2001. 106p. Tese (Doutorado em Zootecnia) - Universidade Estadual Paulista, 2001.

NATIONAL RESEARCH COUNCIL - NRC. Nutrients requirements of beef cattle. 7.ed.rev. Washington, D.C.: National Academy Press, 2000. 232p.

NATIONAL RESEARCH COUNCIL - NRC. Nutrient requirements of goats: Angora, dairy, and meat goats in temperate and tropical countries. Washington, D.C.: National Academy Press, 1981. p.26-48.

OWENS, F.N.; DUBESKI, P.; HANSON, C.F. Factors that alter the growth and development of ruminants. Journal of Animal Science, v.71, p.3138-3150, 1993.

PUTRINO, S.M.; LEME, P.R.; SILVA, S.L. Exigências líquidas de proteína e energia para ganho de peso de tourinhos Brangus e Nelore alimentados com dietas contendo diferentes proporções de concentrado. Revista Brasileira de Zootecnia, v.35, n.1, p.292-300, 2006.

RESENDE, K.T.; PEREIRA FILHO, J.M.; TRINDADE, I.A.C.M. et al. Exigências nutricionais de caprinos leiteiros. In: REUNIÃO ANUAL DA SOCIEDADE BRASILEIRA DE ZOOTECNIA, 38. 2001, Piracicaba. Anais... Piracicaba: Sociedade Brasileira de Zootecnia, 2001. p.284-296. 
SANZ SAMPELAYO, M.R.; LARA, L.; EXTREMERA, F.G. Energy utilization for maintenance and growth in preruminant kid goats and lambs. Small Ruminant Research, v.17, p.25-30, 1995.

SHAHIN, K.A.; BERG, R.T.; PRICE, M.A. The effect of breedtype and castration on tissue growth patterns and carcass composition in cattle. Livestock Production Science, v.35, n.3/4, p.251-264, 1993.

SILVA, D.J.; QUEIROZ, A.C. Análise de alimentos (métodos químicos e biológicos). 3.ed. Viçosa, MG: Universidade Federal de Viçosa, 2002. 235p.

UNIVERSIDADE FEDERAL DE VIÇOSA - UFV. Sistema de Análises Estatísticas e Genéticas - SAEG. Viçosa, MG: Fundação Arthur Bernardes, 2001. 301p.

SOUSA, E.M.H.; QUEIROZ, A.C.; RESENDE, K.T. et al. Exigências nutricionais de caprinos da raça Alpina em crescimento. 2. Composição corporal e do ganho em peso em proteína, extrato etéreo, energia, cálcio e fósforo. Revista Brasileira de Zootecnia, v.27, n.1, p.193-197, 1998.
TEIXEIRA, I.A.M.A Métodos de estimativa da composição corpora e exigências nutricionais de cabritos $F 1$ Boer $x$ Saanen. Jaboticabal: Universidade Estadual Paulista, 2004. 93p. Tese (Doutorado em Zootecnia) - Universidade Estadual Paulista, 2004

VALADARES FILHO, S.C.; PAULINO, P.V.R.; SAINZ, R.D Desafios metodológicos para determinação das exigências nutricionais de bovinos de corte no Brasil. In: REUNIÃO ANUAL DA SOCIEDADE BRASILEIRA DE ZOOTECNIA, 42., 2005, Goiânia. Anais... Goiânia: Sociedade Brasileira de Zootecnia, 2005. p.261-287.

VALADARES FILHO, S.C.; ROCHA JR., V.R.; CAPPELLE, E.R. Tabelas de composição de alimentos para bovinos. 1.ed. Viçosa, MG: Editora UFV, 2002. 297p.

YÁÑEZ, E.A. Desenvolvimento relativo dos tecidos e características da carcaça de cabritos Saanen, com diferentes pesos e níveis nutricionais. Jaboticabal: Universidade Estadual Paulista, 2002. 85p. Tese (Doutorado em Zootecnia) - Universidade Estadual Paulista, 2002. 